This is an Accepted Manuscript of an article published by Taylor \& Francis

in Journal of Interprofessional Care on 28/12/15, available online: http:// www.tandfonline.com/10.3109/13561820.2015.1054478."

\title{
Interprofessional training for nursing and medical students in Norway: Exploring different professional perspectives
}

\author{
Ingunn Aase, Britt Hansen, Karina Aase \\ University of Stavanger \\ Scott Reeves \\ Kingston University \& St George's, University of London
}

\begin{abstract}
This paper presents an explorative case study focusing on interprofessional training for medical and nursing students in Norway. Based on interviews with, and observations of, multiple stakeholder groups - students, university faculty and hospital staff - content analysis was applied to investigate their perspectives regarding the design of such educational training. The findings revealed a positive perspective amongst stakeholders while voicing some concerns related to how communication issues, collaboration and workflow, as well as professional role patterns should be reflected in such training. Based on our data analysis we derive three themes that must be considered for successful interprofessional training of nursing and medical students; Clinical Professionalism, Team Performance and Patientcentered Perspective. These themes must be balanced contingent on the students' background and the learning objectives of future interprofessional training efforts.
\end{abstract}

Keywords: interprofessional education, interprofessional training, interprofessional teamwork, qualitative methods, case study, Nordic context

\section{Introduction}

Studies have repeatedly suggested that interprofessional teamwork and collaboration can be conducive to safer care and better patient outcomes (e.g. Manser, 2009; Reeves, Lewin, Espin \& Zwarenstein, 2010;; Zwarenstein \& Reeves, 2006; Zwarenstein, Goldman \& Reeves, 2009). Similar findings have been reported within the Nordic context (e.g. Clark, 2011; Kyrkjebø, Brattebø, \& Smith-Strøm, 2006). However, challenges persist in creating effective interprofessional teams, and studies suggest the need for improved education and awareness of the significance of interprofessional training (Jeffs et al., 2013; Manser, 2009; Reeves, Perrier, Goldman, Freeth \& Zwarenstein, 2013; Okuyama, Martowirono \& Bijnen, 2011).

In a Nordic context, research conducted mainly in Sweden, but also in Norway and Denmark, has investigated interprofessional training in pre-graduate education, addressing - mostly by quantitative methods - the students' perceptions after having completed their training. None 
of these studies were conducted exclusively with nursing and medical students (Almås \& Barr, 2008; Jacobsen, Fink, Marcussen, Larsen \& Hansen, 2009; Pelling, Kalen, Hammer \& Wahlstrøm, 2011; Wilhelmsson et al., 2009). Two of the studies concluded that nursing students value interprofessional education more highly than other student groups (Almås \& Barr, 2008; Wilhelmsson, Ponzer, Dahlgren, Timpka \& Faresjø, 2011). Wilhelmsson et al. (2009), Jacobsen et al. (2009), and Pelling et al., (2011) suggested that undergraduate students' professional identity would benefit from encounters with members of other professions.

This study analyses a case set in the Norwegian educational system for health professionals; an arena where introduction of interprofessional training has proved difficult in spite of a supportive government health policy (Aase, Aase \& Dieckmann, 2013). To understand these difficulties and suggest improvements for future training efforts, we have interviewed and observed a broad range of relevant stakeholders - including academic supervisors, teachers, hospital staff and students - in an effort to understand their perspectives on the contents of interprofessional training. Previous Nordic studies (Almås \& Barr, 2008; Jacobsen, Fink, Marcussen, Larsen \& Hansen, 2009; Pelling, Kalen, Hammer \& Wahlstrøm, 2011; Wilhelmsson et al., 2009) have queried participants after they have attended interprofessional training sessions, mostly eliciting positive comments. This study is the first in a Nordic setting to gather data prior to the different stakeholders' involvement in interprofessional training efforts.

The aim of this study was to explore the perspectives of relevant stakeholder groups with regard to the contents of interprofessional training in the education of nursing and medical students. This research was done to create a knowledge base and to develop a set of important notions for optimizing the design of future training efforts. By perspectives we mean the ideas, recommendations, examples, and accounts of past experiences that stakeholders associated with interprofessional teamwork or collaboration. Focusing on the contents of training naturally raises questions regarding teaching methodology and instruction techniques. However, these issues are not part of the current study.

\section{Methods}

The study adopted an exploratory case study approach (Yin, 2014) in which the phenomenon explored was the stakeholder groups' perspectives of the content of interprofessional training 
in the education of nursing and medical students. The case context consisted of a regional Norwegian healthcare education setting for nursing and medical students. Specifically, two university faculties (nursing, medicine) and a hospital were involved.

\section{Participants}

The participants consisted of nursing and medical students, clinical supervisors and academic teachers in the educational programs. Table 1 gives an overview of the study participants.

\section{INSERT TABLE 1 ABOUT HERE}

A web site for educational institutions was used to invite the nursing students to participate voluntarily in the study. The medical students were invited by their hospital supervisor. The hospital staff members were identified by their hospital line managers, and invited by email. All but one physician accepted the invitation. The physicians and the nursing supervisors had extensive experience in mentoring students.

\section{Data collection}

Interview data were gathered from focus groups (Morgan, 1997) and individual interviews (Polit \& Beck, 2008). In addition, observations were made at a hospital ward, using an ethnographic approach (Polit \& Beck, 2008; Reeves, Peller, Goldman \& Kitto, 2013). Table 2 depicts the data collection methods and material.

\section{INSERT TABLE 2 ABOUT HERE}

Focus groups and interviews. Each interview was conducted and managed by members of the research team (first and second authors). The focus group interviews took place either in a simulation-based training center or at the hospital. Interviews with staff were done in their workplaces. All interviews were audio-recorded to ensure accuracy and transcribed before analysis.

Both focus group interviews and individual interviews followed a semi-formal interview guide covering the following topics: participants' previous experience with interprofessional teamwork or collaboration; examples of effective and/or dysfunctional interprofessional teamwork or collaboration; topics to include in a future training program; descriptions of a 
well-functioning member - nurse or physician - in interprofessional teamwork or collaboration. ${ }^{1}$

Observations. As part of data collection, the first author spent five days observing the interprofessional interactions that transpired during the daily rounds in a hospital ward. The choice of setting for the observations - daily rounds - was based on the work of Aase, Hansen $\&$ Aase (2014), indicating that students wanted interprofessional training to be extended beyond acute settings. They cited the daily ward rounds as an arena requiring interprofessional collaboration skills. The researcher participated in the "huddle" meetings preceding the daily rounds and the subsequent daily rounds. In addition, the observer remained at the ward for the rest of the day. Guided by a "minimum engagement principle", the observer endeavored to avoid influencing the social processes under study (Reeves, 2008; Yin, 2014). Observations followed an open-ended observation guide, in which the observer mapped the organizational issues, personnel involved, time used, the distribution of various tasks, interprofessional communication, and training-related activities. The field notes were transcribed at the end of each observation day.

\section{Data analysis}

Content analysis was used to elicit categories and themes from the data (Graneheim \& Lundman, 2004). During the analysis meaning units were identified, condensed and coded; enabling the conceptualizing of categories and themes. We adopt the terminology of Graneheim and Lundman (2004), who defined sub-categories and categories as concepts reflecting the "manifest" patterns of the data. A theme, on the other hand, can be thought of as a conceptual construct serving to explain the more "latent" commonalities and patterns stretching across categories (Granheim \& Lundman, 2004). In this study we developed three themes.

While the analysis is mainly inductive - progressing from observations to abstract notions some notions are corroborated by theoretical concepts from the literature, as explained in the discussion section.

Following Polit and Beck (2008) and Graneheim and Lundman (2004), we used collaborative analysis across authors to enrich the reflection on the data and interpretations. The analysis ceased when content and thematic saturation was achieved. Triangulation compared data from 
the focus groups, individual interviews, and observations (Miles \& Huberman, 1994; Graneheim \& Lundman, 2004).

\section{Ethical considerations}

The study was approved by the two universities and the hospital involved, and by the Norwegian Social Science Data Service (Approvals No 28383 and 32881). The hospital's Data Protection Officer approved the field observations. Having been informed of the study objectives and the option to withdraw at any point, the participants signed informed consents. Recordings and transcripts were coded to prevent identification of the participants.

\section{Results}

The data indicated that all stakeholder groups possessed a positive view on interprofessional training. Participants expressed a general consensus concerning the desirability to collaborate and train across professional boundaries, thus providing both students and practitioners with a better basis for teamwork. With few arenas for interprofessional training available, the stakeholders welcomed efforts to bring such training into study programs.

Our analysis elicited a numbers of issues (themes) to take into account when designing the content of interprofessional training. Table 3 shows the structure of these themes, as well as the categories and sub-categories. We start by presenting the manifest content, as captured by the condensed sub-categories and the categories. This is followed by a descriptions of the conceptually constructed themes.

INSERT TABLE 3 ABOUT HERE

Functional communication 
Both learners and staff highlighted the need for precise and comprehensive communication in order to ensure the delivery of quality medical care and treatment. Some informants viewed this mainly as a matter of issuing clear instructions and securing a timely and adequate response. Many of the communication issues in the study can be grouped under the subcategory Instructions and response. However, some participants alleged that an overly precise communication style may prevent certain types of information from surfacing, notably data pertaining to the patient's quality of life, but also to open questions and ongoing debates among the team members. Comments of this nature were categorized under the sub-category Reflection and synergy. Finally, some participants voiced concerns over nurses' reluctance to be more outspoken with their opinions and professional judgments. These data were categorized under the sub-category Command of language. In the following we elaborate upon the three communication sub-categories.

Instructions and response. All stakeholders agreed that interprofessional training should include mandatory practice in clear, concise and timely communication. The "parameters" (factual data) were central to these comments. A nursing student stated:

We have to be concise in our communication with the physicians; reporting exactly what happens to the patient [Nursing Student 2]

A nursing supervisor recommended the use of $\mathrm{SBAR}^{2}$ as a starting point for interprofessional training in concise communication:

I use SBAR when I call the physicians at night or in the evening, for example regarding painkillers to a patient, or if I believe a patient needs to be assessed by a doctor [Nursing Supervisor 1]

According to one of the physicians:

The students need to learn interprofessional communication; it takes time to learn working interprofessionally, but we can give them some tools, such as SBAR and $\mathrm{ABCDE}^{3}$, which they can bring with them into their future institution [Physician 1] 
While largely corroborating these remarks, the hospital ward observations revealed that communication linked to factual data, far from being precise, was frequently ambiguous and unclear. The nurses often responded by saying the parameters were "fine," instead of giving the actual numerical values. Some nurses were aware of these shortcomings:

I feel better as a nurse, if I can respond and provide the parameter values. It is beneficial for all of us if the parameters are ready for the huddle; we save time, and it is also better for the patients [Nursing Supervisor 3]

Reflection and synergy. This sub-category captured the need for a broader and less technical dialogue catering to team management and issues that were not seen as part of the patient's diagnosis, and hence might slip through a streamlined communication scheme. Discussing such issues - which may include the patient's social background - may be crucial for caring for the patient. It was also pointed out that matters not anticipated - such that a need to isolate a patient - may require reflection and debate reaching across professions.

Commenting on the need for functional communication supporting reflection and synergy, a physician stated "let us not educate soloists but rather members of the orchestra" [physician 4]

A medical student had noted that nurses often practiced a richer and more open communication style:

Nurses often use a lot of words in order to describe the patients, while physicians use much fewer words - this may complicate the communication [Medical Student 4]

A nursing teacher commented on the need for communication supporting conflicts and debates, stating that team member sometimes needed to

... being courageous and behaving like the patient's lawyer even if it means arguing against the physician [Nursing Teacher 4]

Finally, some aspects of teamwork seemed to thrive on informal communication. One of the nursing supervisors stated that, "the best pre-visit meetings occur when I can sit with the physician, wondering together" [Nursing Supervisor 4]. 
Together these statements suggest the need for dialogue transcending the medical protocols linked to diagnostic and treatment.

Command of language. This sub-category refers to the ability to define and control the team dialogue. Some of the comments suggested that nurses often failed to put their mark on the ongoing dialogue within the interprofessional team, presumably leading to communication attuned to the needs of the physicians. Several comments assumed that training might help to balance the team dialogue.

One of the nursing supervisors stated that some of her nursing colleagues lacked the confidence to express their opinions. Nursing supervisors and nursing teachers pointed out that:

Nurses [we] are afraid to discuss with the physicians [Nursing Teacher 4]

Physicians are different, with some of them we cannot argue or oppose, or suggest treatment; we just follow up their messages [Nursing Supervisor 6]

I am following the instructions from the physicians; I will not suggest anything [Nursing Supervisor 4]

\section{Collaboration and workflow}

Under this category, several statements indicated a need for a joint understanding of how and in what context the team's tasks were defined. These issues were captured by the two subcategories: Tasks and Accountability, and Responsibility and Engagement, respectively.

Tasks and accountability. The participants expressed different views on what tasks the nurses should be occupied with and held accountable for. Some of the physicians expected the nurses to be spending more of their time "by the bedside," engaging in what they perceived as "fundamental nursing tasks" such as ensuring appropriate nutrition, elimination and physical activity, as well as measuring the parameters. One of the physicians stressed that:

Nursing is both a practical and academic role, and a nurse needs to provide relevant observations and have sufficient medical insight [Physician 4] 
Nurses, in contrast, offered few proposals to the physicians. A nursing supervisor claimed that the physicians were overworked and so she voluntarily did some of their paperwork. One of the nursing teachers stated that:

Sometimes nurses and students are seen as the physicians' assistants and it is difficult to describe what the nurses' own functions are [Nursing Teacher 5]

Field notes from our observation of daily rounds corroborated these views by documenting insecurity among nurses concerning their own tasks related to physicians' expectations. In one of the observations, a nurse appeared to be confused, and when afterwards asked to elaborate she commented: "it is an art to know what they will ask for, but I feel I learn gradually. I feel it is stressful and I sometimes get worried" [Observation 3]

Responsibility and engagement._This sub-category conveyed the stakeholders' inclination and capability for taking responsibility independently of what they were formally accountable for. The concept was linked to engagement, initiative and proactive behavior. One of the physicians commented on the nurses as follows:

Nothing happens before they are instructed to act, then they do what they are told to do. They should be more dynamic. They should have a notion about the expected progression; it should not come as a surprise [Physician 1]

During ward observations we saw this issue played out in practice by relatively low levels of engagement in interprofessional interactions. When asked to explain what we had observed, one of the nurses commented the following:

Nurses should be more active and not afraid to discuss with the physicians. I would like to have better knowledge and overview when attending the daily rounds, and I would like to make my own system [Observation 4]

\section{Roles and expectations}

Comments linked to the enduring influence of professional roles were captured under this category. The sub-categories Professional Inequality and Perspective indicated that roles were linked to role-specific cognitive perspectives that served to define what team activities were considered necessary and meaningful. 
Professional inequality. Many nursing students and supervisors expressed concern over what they perceived as the physicians' dominating role in interprofessional collaboration. However, the dominance was largely accepted, as seen from a number of somewhat resigned statements such as "we cannot argue or propose treatment" [Nursing Student 6] and "we learn to follow orders and not discuss options with the physicians" [Nursing Student 5]. Nurses that did not accept this position responded by statements such as "nurses need to learn to speak up" [Nursing Supervisor 6].

During the ward observations a role conflict set off a debate akin to micro-level negotiations following a huddle, as exemplified by the following field note extract:

\footnotetext{
A physician complained that the nurses should have measured and compiled the 'parameters' prior to the daily ward round. The nurse then responded: "This does not work in our group; then we would need a completely different organizing, and we would need to start at six a.m. Then he (the physician) should rather come earlier and obtain the data himself." Rather than agreeing to measure the parameters before the huddle, the nurse then suggested informing the physician if the "condition of the patient had changed" [Observation 4]
}

Some physicians and medical students wanted nurses to be more assertive, to which end they encouraged the nursing teachers to act as role models for the nursing students. A physician pointed out that this would require - in his view - the nursing teachers to spend more time on clinical tutoring. He explained:

We try to be role models for the medical students and, we encourage the nursing teacher to do the same for the nursing students. They should work 50 percent in clinic and 50 percent at the university [Physician 1] 
Perspective. Statements that alluded to the patients' quality of life, social situation, and role fall under this subtheme. These issues were raised mainly by nurses, perhaps reflecting some of the core values in nursing education. In discussions of the daily rounds, a nurse asked, "what about the patients? Can we really let them wait for so long?" [Nursing Supervisor 3]. Despite this remark, most of the comments and ideas offered by the stakeholders were made from the perspective of the members of the nursing or medical professions.

The ward observations showed that the patient-centered perspective had been adopted in uniprofessional dialogues - especially during the daily nursing meetings - rather than in interprofessional conversations. An example of this was a remark made by a nurse in the nursing meeting concerning a patient who desperately wanted to be discharged even if this might put her at risk: "I really think we should place more emphasis on her opinion" [Observation 2].

Some participants wondered about the purpose and function of the daily huddle. One medical student said, "I do not know if the pre-visit is for the doctors or the patient" [Medical Student 6]. Similar concerns were raised about the hospital organization more generally. A nursing teacher asked, "with reference to Pierre Bourdieu; who is controlling the field? Is it the physicians - because they have most of the capital ${ }^{4}$ ?" [Nursing Teacher 5]

The second stage of our analysis focused on themes stretching across the manifest categories. Comparative coding suggested that two themes permeated all categories: Clinical Professionalism and Team Performance. These themes can be understood as perspectives, or different ways of assessing (making sense out of) the multifaceted challenge of interprofessional teamwork.

The Clinical Professionalism theme is based on a diseased oriented understanding, seeing the patient as a malfunctioning entity that warrants "repair" by clinical procedures, frequently assisted by advanced technology and standardized procedures, including SBAR and similar communication tools. Under critical circumstances - such as with life threatening injuries all the stakeholders acknowledged the priority of clinical professionalism. It was accepted that the most competent person in the team should make decisions, and that tasks should be delegated by instructions, without debate. However, the emphasis on clinical professionalism frequently led to an exaggerated reliance on the physicians, representing the most "clinically 
skilled" profession. The same reasoning seemed to imply that nurses and nursing students should restrain their engagement and refrain from voicing their opinions.

An alternative perspective was expressed by the theme Team Performance, which implied understanding the care and treatment provided to the patient, primarily as products of teamwork. Through the teamwork-lenses, the data and observations were subject to new assessments. For example, a decision made by a physician without consulting with the other team members, appeared entirely reasonable from a Clinical Professionalism perspective. From a Team Performance perspective, however, the physician's behavior seemed to violate the rules of the team. Reflecting on the Team Perspective of their work, nursing supervisors admitted this perspective made them feel more satisfied with their work. The team setting conferred value to informal conversations that served to consolidate the team. Even conflict and debates attained meaning in providing a platform for negotiations and team development.

Furthermore, our analysis also led to a third theme, called Patient-centered Perspective, which implied looking at interprofessional teamwork "through the eyes of the patient," and "posing as the patient's advocate." During a discussion of whether patients should have to endure longer waiting before the daily round, a nurse was concerned not with the clinical consequences - but with how the patients would experience the delay. Another nurse suggested the patient's opinion should be given more consideration, and a third wanted to "stand up" for the patient even if it led to conflicts within the team. In these examples, the health professionals argued for assessing the situation from the perspective of the patient.

\section{Discussion}

The structure of the themes described above is not aligned with disciplines or stakeholder groups. A nurse could address an issue in light of Clinical Professionalism in one minute but change her perspective to Team Performance the next. Even so, compared with nurses and nursing students, the physicians and medical students appeared to be more inclined towards a communication style grounded in Clinical Professionalism. Nurses and nursing students tended to adopt a Team Performance perspective that thrived on broader and less formalized communication better suited for team maintenance, collaboration and development through negotiations (e.g. Allen, 1997; Reeves et al., 2009; Strauss, 1978; Strauss et al., 1963). 
The above differences in perspectives and communication styles may shed light on why nurses and physicians mutually criticized each other for failing to communicate appropriately. The physicians and medical students also questioned the nursing role; portraying nurses as unwisely removed from the bedside, passively awaiting instructions and displaying little initiative. We surmise that the nurses' apparently meek behavior were linked to their perception of themselves as team members; with little team leadership, the nurses' performance deteriorated.

The third theme Patient-centered Perspective is indebted to the notion of patient-centered care, hailed by many as key to modernizing health care (Mead \& Bower, 2002; Peplau, 1998) and being "designed to promote the active participation of each discipline in patient care" (Herbert, 2005).

Resonating with the above, Thistletwaite (2012) argued that patient-centered care is a key notion in interprofessional education. However, the idea of patient-centered care has been subject to different interpretations resulting in some ambiguity (Epstein \& Street, 2011), leading us to adopt the more "neutral" term of a Patient-centered Perspective.

While this perspective was promoted by stakeholders, our analysis suggested that the absence of a Patient-centered Perspective was more striking than the comments centered upon it. This phenomenon - nick-named "the disappearing patient" - raises concern, especially since identifying with the patient, acting as the patient's "advocate," holds a central place in modern nursing theory and education (Antrobus, 1997; Norwegian Ministry of Education and Research, 2008; Peplau, 1998). The evasive Patient-centered Perspective may be discussed in light of the work by Menzies-Lyth et al (1970) who concluded that under stress, health care team members may - mostly unconsciously - direct their attention away from the patient and towards maintaining team relations.

Reverting to the two first themes; Clinical Professionalism and Team Performance, we hypothesize that both perspectives are essential to a well-functioning hospital team and that health professionals in interprofessional teams must balance the relative weight attributed to the two. The balance must arguably be tuned to the circumstances; working in an intensive care ward with inexperienced staff may for example warrant the prioritization of Clinical Professionalism. 
In addition to the above balance, we suggest that successful interprofessional teamwork relies on a concerted effort to include the theme of Patient-centered Perspective. The three themes should be given appropriate relative weight, depending on the circumstances. In the case of an educational setting, the students must as a minimum familiarize with all three themes.

\section{Concluding comments}

Based on a qualitative analysis of data obtained from multiple stakeholder groups - students, university faculty and hospital staff, this study has documented their perspectives on interprofessional training of medical and nursing students in Norway. The findings revealed a positive attitude towards interprofessional training, but also unveiled some concerns related to how communication issues, collaboration and workflow and professional role patterns should be incorporated in such training. Some disparities existed between the professional groups. The power relationship between nurses and physicians were found to be markedly asymmetric in favor of the physicians. The physicians' command of language and dialogue were perceived to deter nurses from voicing their concerns during interprofessional work.

Based on our analysis we suggest that three themes of interprofessional teamwork must be considered when designing successful training: Clinical Professionalism, Team Performance and Patient-centered Perspective. These perspectives (themes) should be balanced with appropriate relative weight, contingent on the students' background and the learning objectives.

Physicians and medical students were inclined to a language conducive to Clinical Professionalism, which implied precise and unambiguous communication in order to support clinical treatment - often based on advanced technology. Nursing teachers and nursing students expressed a need for a broader and more informal dialogue, suitable for maintaining team relations. The Patient-centered Perspective was notably difficult to discern in the study; a result that may be due to the stakeholders directing their attention away from the patient and towards maintaining Team Performance. 


\section{End notes}

1. All of the participants spoke Norwegian, which was the language of the interviews. Translation inevitably introduces the risk of some loss of meaning, particularly when statements have been uttered in informal settings. Nevertheless, English and Norwegian are fairly similar languages, to the point that most statements - including many colloquialisms may be translated directly without change of meaning. In cases where the translation of quotes may introduce ambiguity, we have added comments to explain and clarify the meaning. Frequently appearing in the interview material, the term "parameters" is used by healthcare workers to denote a set of clinical data - including blood pressure, body temperature, heart rate and respiratory frequency - that tend to follow each patient. To "obtain" or "measure the parameters" is the same as to take vital signs.

2. SBAR - Situation, Background, Assessment and Recommendation - is a communication tool constructed to function as a checklist and to structure the team's exchange of information (Haig, Sutton \& Whittington, 2006).

3. ABCDE - Airway, Breathing, Circulation, Disability, Exposure - is a communication protocol for immediate patient assessment recommended by the Resuscitation Council of the United Kingdom (2008).

4. The citation is translated directly from Norwegian. We have interpreted the term "capital," to refer to Bourdieu's concept of "cultural capital" (Bourdieu, 1989).

\section{Acknowledgements}

We thank all the participants, the university faculty and the regional hospital for contributing to this study.

\section{Declaration of interest}

This study was accomplished with financial support from The Laerdal Foundation for Acute Medicine under support number 1007. The authors declare no conflicts of interest. The authors alone are responsible for the writing and content of the paper.

\section{References}

Aase, I., Aase, K. \& Dieckmann, P. (2013 ).Teaching interprofessional teamwork in medical and nursing education in Norway: A content analysis. Journal of Interprofessional Care, (3):238-45.

Aase, I, Hansen, B.S., \& Aase, K. (2014). Norwegian nursing and medical students' perception of interprofessional teamwork: A qualitative study. BMC Medical Education, 14:170. 
Allen, D: (1997). The nursing-medical boundary: A negotiated order? Sociology of Health and Illness, 19(4), 498-520.

Almås, S. \& Barr, H. (2008). Common curricula in Norway: Differential implementation and differential outcomes in undergraduate health and social care education. Journal of Interprofessional Care, 2 (6), 650-657.

Antrobus, S. (1997). Developing the nurse as a knowledge worker in health - learning the artistry of practice. Journal of Advanced Nursing, 25, 829-835.

Bourdieu, P. (1986). The Forms of Capital, in J.G. Richardson (Ed.): Handbook of Theory and Research for the Sociology of Education. New York: Greenwood Press.

Clark, P. G. (2011). Examining the interface between interprofessional practice and education: Lessons learned from Norway for promoting teamwork. Journal of Interprofessional Care, 25(1), 26-32. doi:10.3109/13561820.2010.497751

Epstein, R.M., \& Street, R.L. (2011). The Values and Value of Patient-Centered Care. Annals of Family Medicine. 9(2), 100-103.

Graneheim, U.H. \& Lundman, B. (2004). Qualitative content analysis in nursing research: Concepts, procedures and measures to achieve trustworthiness. Nurse Education Today, 24(2), 105-12.

Haig, K., Sutton, S. \& Whittington, J. (2006). SBAR: A shared mental model for improving communication between clinicians. Joint Commission Journal on Quality and Patient Safety, 32, 167-175.

Herbert, C. (2005). Changing the culture: interprofessional education for collaborative patient-centered practice in Canada. Journal of Interprofessional Care, 19 (Suppl.1), 1-4.

Kyrkjebø, J.M., Brattebø, G., \& Smith-Strøm, H. (2006). Improving patient safety by using simulation training in health professional education. Journal of Interprofessional Care, 20 (5), 507-516.

Jacobsen F., Fink A.M., Marcussen V., Larsen K., \&Hansen T.B. (2009). Interprofessional undergraduate clinical learning: Results from a three-year project in a Danish interprofessional training unit. Journal of Interprofessional Care, 23(1):30-40. doi: $10.1080 / 13561820802490909$.

Jeffs, L., Abramovich, I A., Hayes, C., Smilth, O., Tregunno, D., Chan, W.H., \& Reeves, S. (2013). Implementing an Interprofessional patient safety learning initiative: Insights from participants, project leads and steering committee members. BMJ Quality \& Safety, 22, 923-930. doi: 10.1136/bmjqs-2012-001720.

Manser, T. (2009). Teamwork and patient safety in dynamic domains of healthcare: A review of the literature. Acta Anaesthesiologica Scandinavica, 53 (2), 144-151. DOI:

10.1111/j.1399-6576.2008.01717. 
Mead, N. \& Bower, P. (2002). Patient-centered consultation and outcomes in primary care: A review of the literature. Patient Education and Counseling, 48:51-61.

Menzies- Lyth, I. (1970). The functioning of social systems as a defence against anxiety. Institute of Human Relations, London.

Miles, M.B. \& Huberman, A.M. (1994). Qualitative data analysis. Thousand Oaks; CA; Sage Publications.

Morgan D.L. (1997). Focus groups as qualitative research [vol. 16].Thousand Oaks: Sage Publication.

Norwegian Ministry of Education and Research. (2008). Retrieved from http://www.regjeringen.no/upload/KD/Vedlegg/UH/Rammeplaner/ Helse/Rammeplan_sykepleierutdanning_08.pdf. Rammeplan for sykepleierutdanningen. (National Curriculum Regulations for Nursing programmes). Oslo: Author.

Okuyama, A., Martowirono, K., Bijnen, B.(2011). Assessing the patient safety competencies of healthcare professionals: A systematic review. BMJ Quality and Safety, 20, 991-1000.

Pelling S, Kalen A, Hammar M, Wahlström O. (2011). Preparation for becoming members of health care teams: Findings from a 5-year evaluation of a student interprofessional training ward. Journal of Interprofessional Care, 25(5), 328-332.

Peplau, H. (1988). Interpersonal relations in nursing, Macmillan Press.

Polit, D.F., \& Beck, C.T. (2008). Nursing research: Generating and assessing evidence for nursing practice. Philadelphia Lippincott Williams \& Wilkins.

Reeves, S. el al. (2009). Interprofessional interaction, negotiation and non-negotiation on general internal medicine wards. Journal of Interprofessional Care, 23:633-645.

Reeves, S., Lewin, S., Espin, S., \& Zwarenstein, M. (2010). Interprofessional teamwork for health and social care. UK: Wiley- Blackwell.

Reeves S, Peller J, Goldman J, Kitto S (2013) Ethnography in Qualitative Educational Research: AMEE Guide No. 80. Medical Teacher; 35: e1365-e1379

Reeves S, Perrier L, Goldman J, Freeth D, Zwarenstein M (2013). Interprofessional education: effects on professional practice and healthcare outcomes (update). Cochrane Database of Systematic Reviews 2013, Issue 3. Art. No.: CD002213.

Resuscitation Council UK (2008). Advanced life support. Fifth Edition. RCUK, London.

Strauss, A. (1978). Negotiations: Varieties, contexts, processes and social order. Jossey-Bass: San Francisco. 
Strauss, A.L., Schatzman, L., Ehrlich, D. Bucher, R., \& Sabshin, M (1963). The hospital and its negotiated order. In E. Freidson, (Ed.). The hospital in modern society (pp.147-169). London: Collier MacMillan.

Thistletwaite, J. (2012). Interprofessional education: A review of the context, learning and the research agenda. Medical Education, 46: 58-70.

Wilhelmsson, M., Pelling, S., Ludvigsson, J., Hammar, M., Dahlgren, L.O., \& Faresjo, T. (2009).Twenty years experiences of interprofessional education in Linkoping--groundbreaking and sustainable. Journal of Interprofessional Care, 23(2), 121-133.

Wilhelmsson, M., Ponzer, S., Dahlgren, L.O., Timpka, T., Faresjö, T. (2011). Are female students in general and nursing students more ready for teamwork and interprofessional collaboration in healthcare? BMC Medical Education, 21, 11-15.

Zwarenstein M. \& Reeves S. (2006). Knowledge translation and interprofessional collaboration: where the rubber of evidence based care hits the road of teamwork. Journal of Continuing Education in the Health Professions, 26, 46-54.

Zwarenstein, M., Goldman,J. \& Reeves, S. (2009). Interprofessional collaboration: Effects of practice-based interventions on professional practice and healthcare outcomes (Review). The Cochrane Collaboration.

Yin, R.K. (2014). Case study research: design and methods. Thousand Oaks, CA; Sage Publications 
Table 1: Details on the study participants

\begin{tabular}{|l|l|c|}
\hline Interview participants & Details & Numbers \\
\hline $\begin{array}{l}\text { Nursing Students } \\
\text { (Learners) }\end{array}$ & In the third year of their nursing curriculum & 10 \\
\hline $\begin{array}{l}\text { Medical Students } \\
\text { (Learners) }\end{array}$ & In the fourth year of their medical curriculum & 12 \\
\hline $\begin{array}{l}\text { Physicians } \\
\text { (Staff) }\end{array}$ & Affiliated with both the hospital and the university & 4 \\
\hline $\begin{array}{l}\text { Nursing supervisors } \\
\text { (Staff) }\end{array}$ & Employed by the hospital & 6 \\
\hline $\begin{array}{l}\text { Nursing teachers } \\
\text { (Staff) }\end{array}$ & Employed by the university & 6 \\
\hline
\end{tabular}


Table 2: Details on data collection and participant involvement

\begin{tabular}{|l|l|}
\hline Data collection method & Participants \\
\hline $\begin{array}{l}\text { Focus group interviews } \\
\text { (audiotaped) }\end{array}$ & $\begin{array}{l}\text { 22 students: } \\
\text { Focus group 1: seven medical students } \\
\text { Focus group 2: four nursing students } \\
\text { Focus group 3: three medical and four nursing students } \\
\text { Focus group 4: two medical and two nursing students }\end{array}$ \\
\hline $\begin{array}{l}\text { Observations of } \\
\text { interprofessional } \\
\text { teamwork at hospital } \\
\text { (field notes) }\end{array}$ & Nurses and physicians during day-shifts (25 hours) \\
\hline $\begin{array}{l}\text { Focus group interviews } \\
\text { (audiotaped) }\end{array}$ & $\begin{array}{l}\text { 12 nursing supervisors: } \\
\text { Focus group 1: six nursing teachers } \\
\text { Focus group 2: four nurses } \\
\text { Focus group 3: two nurses }\end{array}$ \\
\hline $\begin{array}{l}\text { Individual interviews } \\
\text { (audiotaped) }\end{array}$ & Four physician supervisors \\
\hline
\end{tabular}


Table 3: Themes, Categories and Sub-categories to explain stakeholders' perspectives on the contents of interprofessional training

\begin{tabular}{|c|l|l|l|}
\hline $\begin{array}{c}\text { Themes } \\
\text { (stretching across } \\
\text { categories) }\end{array}$ & $\begin{array}{l}|l| \\
\text { Clinical Professionalism, Team Performance, Patient Centered } \\
\text { Perspective }\end{array}$ \\
\hline \multirow{2}{*}{ Categories } & $\begin{array}{l}\text { Functional } \\
\text { communication }\end{array}$ & $\begin{array}{l}\text { Collaboration and } \\
\text { workflow }\end{array}$ & $\begin{array}{l}\text { Roles and } \\
\text { expectations }\end{array}$ \\
\hline \multirow{2}{*}{ Sub-categories } & $\begin{array}{l}\text { Instruction and } \\
\text { responses }\end{array}$ & $\begin{array}{l}\text { Tasks and } \\
\text { accountability }\end{array}$ & $\begin{array}{l}\text { Professional } \\
\text { inequality }\end{array}$ \\
\cline { 2 - 4 } & $\begin{array}{l}\text { Reflection and } \\
\text { synergy }\end{array}$ & $\begin{array}{l}\text { Responsibility and } \\
\text { engagement }\end{array}$ & Perspective \\
\cline { 2 - 4 } & $\begin{array}{l}\text { Command of } \\
\text { language }\end{array}$ & & \\
\hline
\end{tabular}

